Ambiente \& Água - An Interdisciplinary Journal of Applied Science
ISSN 1980-993X - doi:10.4136/1980-993X
www.ambi-agua.net
E-mail: ambi-agua@agro.unitau.br

\title{
Dias trabalháveis para o manejo do solo em função da chuva e da disponibilidade hídrica do solo em diferentes regiões brasileiras
}

\author{
doi: 10.4136/ambi-agua.1389
}

Received: 04 May 2014; Accepted: 17 Jun 2014

\author{
Leonardo Amaral Monteiro ${ }^{1 *}$; Paulo Cesar Sentelhas ${ }^{1}$; \\ Sônia Maria De Stefano Piedade ${ }^{2}$ \\ ${ }^{\mathbf{1}}$ Universidade de São Paulo (USP) Escola Sup. de Agricultura "Luiz de Queiroz", Piracicaba, SP, Brasil \\ Departamento de Engenharia de Biossistemas \\ ${ }^{2}$ Universidade de São Paulo (USP) Escola Sup. de Agricultura "Luiz de Queiroz", Piracicaba, SP, Brasil \\ Departamento de Ciências Exatas \\ *Autor correspondente: e-mail: monteiroleonardo6@gmail.com, \\ pcsentel.esalq@usp.br, soniamsp@usp.br
}

\section{RESUMO}

O uso de maquinário nos sistemas agrícolas está se tornando cada vez mais intensivo levando à compactação ou degradação dos solos quando o manejo desses é feito em condições inadequadas, o que vem contribuindo para o decréscimo das produtividades agrícolas. Com base nisso, o objetivo deste trabalho foi definir os períodos do ano mais apropriados para a realização das operações mecanizadas de preparo de solo em algumas localidades brasileiras onde a agricultura é atividade de relevante impacto econômico. Foram utilizados dados históricos diários de chuva e temperatura do ar das localidades de Piracicaba, SP, Passo Fundo, RS, Londrina, PR, e Dourados, MS. As condições eram consideradas favoráveis ao preparo do solo quando o dia apresentava chuva diária menor do que $5 \mathrm{~mm}$ e o armazenamento relativo de água do solo entre 40 e 90\% da capacidade de água disponível, sendo este último determinado por meio do balanço hídrico sequencial diário empregando-se o modelo de Thornthwaite e Mather (1955), para uma capacidade de água disponível de 100 $\mathrm{mm}$, valor representativo dos solos dessas regiões. A partir da cadeia de Markov foram calculadas as probabilidades condicionais, com as quais se determinou os dias consecutivos aptos às atividades mecanizadas em cada decêndio ao longo do ano, sendo, portanto, uma ferramenta importante para o planejamento dos períodos mais adequados ao emprego de máquinas para o preparo e manejo do solo. A variabilidade anual das chuvas e do armazenamento de água no solo permitiu identificar os períodos do ano com favorabilidades baixa, média e alta às operações com máquinas para o preparo e manejo do solo. Dentre as localidades analisadas houve predomínio do número médio de dias trabalháveis entre 11 e 20 dias na grande maioria dos meses, exceto para Londrina onde houve uma maior predominância de um baixo número de dias trabalháveis ao longo do ano, ou seja, com até 10 dias.

Palavras-chave: probabilidades simples e condicionais, cadeia de Markov, preparo do solo. 


\title{
Working days for soil management as a function of rainfall and soil moisture in different Brazilian regions
}

\begin{abstract}
The use of machinery in agriculture is increasing. This leads to soil compaction or degradation when the machinery is operated under inappropriate soil conditions, which in turn results in decreasing crop yields. Therefore, the aim of this study was to identify the periods of the year when it is appropriate to use machinery for soil management, as a function of rainfall and soil moisture, in traditional agricultural regions in southern Brazil. The study used daily rainfall and air temperature data from Piracicaba, SP, Passo Fundo, RS, Londrina, PR and Dourados, MS, Brazil. Favorable conditions were calculated considering daily rainfall lower than $5 \mathrm{~mm}$ and soil moisture between 40 and $90 \%$ of soil water holding capacity. Daily soil water balance was calculated by the Thornthwaite and Mather (1955) method, for a soil water holding capacity of $100 \mathrm{~mm}$, which represents the main soils of the studied regions. The Markov chain was applied and used to calculate the conditional probabilities which were used for estimating the sequential working days in each ten-day period throughout the year. The working days technique is an important tool for determining the most appropriate periods of the year for soil management. The annual rainfall and soil moisture variability was used to identify the periods of the year with low, medium and high suitability for soil management. For the assessed locations, there was a predominance of 11 to 20 working days per month, except for Londrina where up to 10 working days per month predominated.
\end{abstract}

Keywords: simple and conditional probabilities, Markov chain, soil management.

\section{INTRODUÇÃO}

A intensificação das operações mecanizadas, se realizadas em condições desfavoráveis, podem causar a compactação ou desestruturação do solo, além de outros impactos ambientais (Hemmat et al., 2009). Devido a isso, as atividades agrícolas mecanizadas devem ser realizadas considerando-se as condições edafo-climáticas vigentes, de modo a se preservar o potencial produtivo de cada região.

De acordo com Costa et al. (2003), além das características do solo, as condições climáticas aliadas ao sistema de manejo e umidade do solo no momento da realização das operações são fatores decisivos no grau de impacto ocasionado pelo uso de máquinas e implementos agrícolas no preparo do solo. Essa operação é a que mais influencia os atributos físicos do solo, determinando o tamanho e a relação entre macro e microporos, a capacidade de retenção da água proveniente da chuva e da irrigação e o crescimento das raízes (Zanetti et al., 2007).

Com o aumento do uso de máquinas no campo, as operações acabam sendo realizadas frequentemente sob condições climáticas e de umidade do solo inadequadas, comprometendo diretamente a qualidade estrutural do solo (Oliveira et al., 2003). Na região Centro-Sul do Brasil, de acordo com Souza et al. (2005), isso vem ocorrendo devido ao aumento das atividades mecanizadas, especialmente no setor sucroalcooleiro, o que tem acarretado no processo de compactação da camada arável (Camilotti et al., 2005).

Sendo assim, estudos voltados à geração de informações relacionadas às condições edafo-climáticas adequadas ao manejo moto-mecanizado do solo é de grande importância (Rowhani et al., 2011), uma vez que isso representa uma parcela significativa do custo de produção (Silva et al., 2002).

Se por um lado o manejo do solo sob alta umidade resulta em compactação, por outro, quando o emprego de maquinário é feito com baixa umidade do solo, o processo de 
desestruturação é potencializado, aumentando o risco de erosão (Severiano et al., 2008). Assim, deve-se evitar o manejo do solo sob tais condições de modo a minimizar esse processo e aumentar a sustentabilidade dos sistemas agrícolas, já que o manejo adequado dos solos é importante para que as suas características físicas não se tornem limitantes para o crescimento e desenvolvimento do sistema radicular das culturas, para a absorção de água e nutrientes pelas raízes (Martin-Vertedor e Dodd, 2011) e para a produtividade das culturas (Chen e Weil, 2011).

Com o intuito de determinar as condições edafo-climáticas adequadas para a entrada de máquinas no campo, o método da cadeia de Markov de primeira ordem vem sendo empregado (Ataíde et al., 2012). Primeiramente, esse procedimento foi utilizado para a determinação de períodos secos e chuvosos em Israel (Gabriel e Neumann, 1962), porém apresentando-se como uma ferramenta potencial para a definição dos períodos do ano mais adequados para operações de preparo e manejo do solo (Erthal e Sentelhas, 1995; Ataíde et al., 2012).

Desse modo, o objetivo do presente estudo foi definir os períodos do ano mais apropriados para a realização das operações mecanizadas de preparo e manejo do solo em diferentes regiões agrícolas brasileiras por meio da aplicação do método da cadeia de Markov.

\section{MATERIAL E MÉTODOS}

O presente estudo empregou dados meteorológicos diários do período compreendido entre 1980 e 2008 , considerando-se as seguintes variáveis: temperatura média do $\operatorname{ar}\left({ }^{\circ} \mathrm{C}\right)$ e precipitação pluvial $(\mathrm{mm})$. Esses dados foram obtidos para as seguintes localidades:

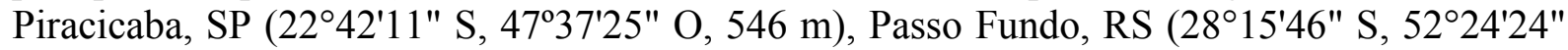

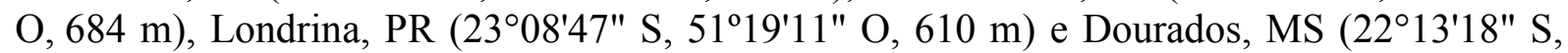
$54^{\circ} 48^{\prime} 23^{\prime \prime} \mathrm{O}, 430 \mathrm{~m}$ ), as quais representam regiões tradicionais de cultivo das principais culturas do agronegócio brasileiro, em que as operações agrícolas de preparo e manejo do solo são frequentes.

Com o intuito de determinar as probabilidades de ocorrência de dias favoráveis (F) ao tráfego de máquinas no campo para o preparo e manejo do solo, considerou-se que o conteúdo percentual de água no solo (armazenamento relativo) ideal para as operações de manejo do solo deveria estar entre 40 e 90\% da capacidade de água disponível (CAD) (Rücknagel et al., 2012), limites considerados críticos já que acima de $90 \%$ e abaixo de $40 \%$ da CAD os riscos, respectivamente, de compactação e de desestruturação dos solos são potencializados (Erthal e Sentelhas, 1995; Ataíde et al., 2012). A contabilização do armazenamento diário de água no solo foi realizada por meio do balanço hídrico climatológico sequencial diário, utilizando o modelo de Thornthwaite e Mather (1955), no qual a evapotranspiração de referência foi estimada pelo método de Thornthwaite com a temperatura efetiva (Camargo et al., 1999). A CAD considerada para a confecção dos balanços hídricos foi de $100 \mathrm{~mm}$, valor considerado representativo dos latossolos que predominam nas regiões de estudo, como observado por Teramoto et al. (2001) para Piracicaba, SP, por Spera et al. (2008) para Passo Fundo, RS, por Araujo et al. (2004) para Londrina, PR, e por Gomes et al. (2007) para Dourados, MS. Além do armazenamento relativo de água no solo, considerou-se também como condição de favorabilidade o fato da precipitação diária ser inferior a $5 \mathrm{~mm}$ (Erthal e Sentelhas, 1995; Aviad et al., 2009; Ataíde et al., 2012).

Por meio da cadeia de Markov de primeira ordem, foram calculadas as probabilidades condicionais de ocorrência de dias favoráveis (F) e não favoráveis (NF) ao trabalho com máquinas no campo, de acordo com os critérios apresentados, possibilitando o cálculo de dias consecutivos favoráveis às operações moto-mecanizadas. A seguir são apresentadas as equações (Equações 1 a 6) utilizadas para o cálculo das probabilidades simples e condicionais para cada decêndio do ano, com base em dados diários: 


$$
\begin{aligned}
& \mathrm{P}(\mathrm{F})=\frac{\mathrm{F}}{\mathrm{N}} \\
& \mathrm{P}(\mathrm{NF})=1-\mathrm{P}(\mathrm{F}) \\
& \mathrm{P}(\mathrm{F} / \mathrm{F})=\frac{\mathrm{F} / \mathrm{F}}{\mathrm{F}} \\
& \mathrm{P}(\mathrm{NF} / \mathrm{F})=1-\mathrm{P}(\mathrm{F} / \mathrm{F}) \\
& \mathrm{P}(\mathrm{NF} / \mathrm{NF})=\frac{\mathrm{NF} / \mathrm{NF}}{\mathrm{NF}} \\
& \mathrm{P}(\mathrm{F} / \mathrm{NF})=1-\mathrm{P}(\mathrm{NF} / \mathrm{NF})
\end{aligned}
$$

em que:

N é o número total de dias;

F é o número de dias favoráveis;

NF é o número de dias não favoráveis;

$\mathrm{P}(\mathrm{F} / \mathrm{F})$ é a probabilidade de ocorrência de um dia ser favorável dado que o dia anterior foi favorável;

$\mathrm{P}(\mathrm{NF} / \mathrm{F})$ é a probabilidade de um dia não ser favorável dado que o dia anterior foi favorável;

$\mathrm{P}(\mathrm{F} / \mathrm{NF})$ é a probabilidade de ocorrência de um dia favorável dado que o dia anterior não foi favorável; e

$\mathrm{P}(\mathrm{NF} / \mathrm{NF})$ é a probabilidade de ocorrência de um dia ser não favorável dado que o dia anterior não foi favorável.

Determinou-se, para a escala diária, a variabilidade média ao longo do ano da probabilidade de ocorrência de dias trabalháveis, assim como o número de anos em que cada dia do ano foi considerado como favorável às operações moto-mecanizadas de preparo e manejo do solo. Para a caracterização dos meses do ano em relação à favorabilidade, foram admitidas três classes: alta favorabilidade (A), meses que contem mais de 20 dias favoráveis; média favorabilidade (M), meses com 11 a 20 dias favoráveis; e baixa favorabilidade (B), meses com até 10 dias favoráveis. Assim sendo, determinaram-se as épocas do ano em que ocorrem as condições edafo-climáticas mais favoráveis às operações moto-mecanizadas de manejo do solo, assim como as épocas em que as condições ambientais não foram adequadas ao emprego de máquinas para preparo do solo, tanto pela ocorrência de chuvas elevadas como pelo excesso ou falta de umidade de água no solo.

Após o cálculo das probabilidades condicionais, foi utilizada uma equação "geométrica" (Equação 7) a qual é função da probabilidade condicional obtida por meio da cadeia de Markov, para a estimativa das probabilidades sequenciais médias dos dias favoráveis em cada decêndio do ano, conforme proposto por Robertson (1976):

$$
\mathrm{P}(\mathrm{n})=\mathrm{P}(\mathrm{F}) \times \mathrm{P}(\mathrm{F} / \mathrm{F})^{\mathrm{n}-1}
$$

em que:

$\mathrm{P}(\mathrm{n})$ é a probabilidade de ocorrência de " $\mathrm{n}$ " dias consecutivos favoráveis ao manejo do solo com maquinário. A partir dessa equação foi realizada a análise decendial das probabilidades de ocorrência de dias favoráveis consecutivos em cada local, de modo a gerar 
uma ferramenta de suporte ao planejamento das atividades agrícolas de manejo e preparo do solo ao longo do ano nas localidades analisadas.

\section{RESULTADOS E DISCUSSÃO}

A Figura 1 apresenta a variabilidade média diária anual da precipitação, do armazenamento relativo de água no solo (ARAS) e do número relativo de anos em que cada dia é favorável às operações moto-mecanizadas de preparo e manejo do solo, ou seja, trabalhável. Com base na Figura 1 é possível identificar as tendências que essas variáveis seguem ao longo do ano, apresentando um indicativo das épocas mais adequadas para as operações de manejo do solo nas localidades avaliadas.

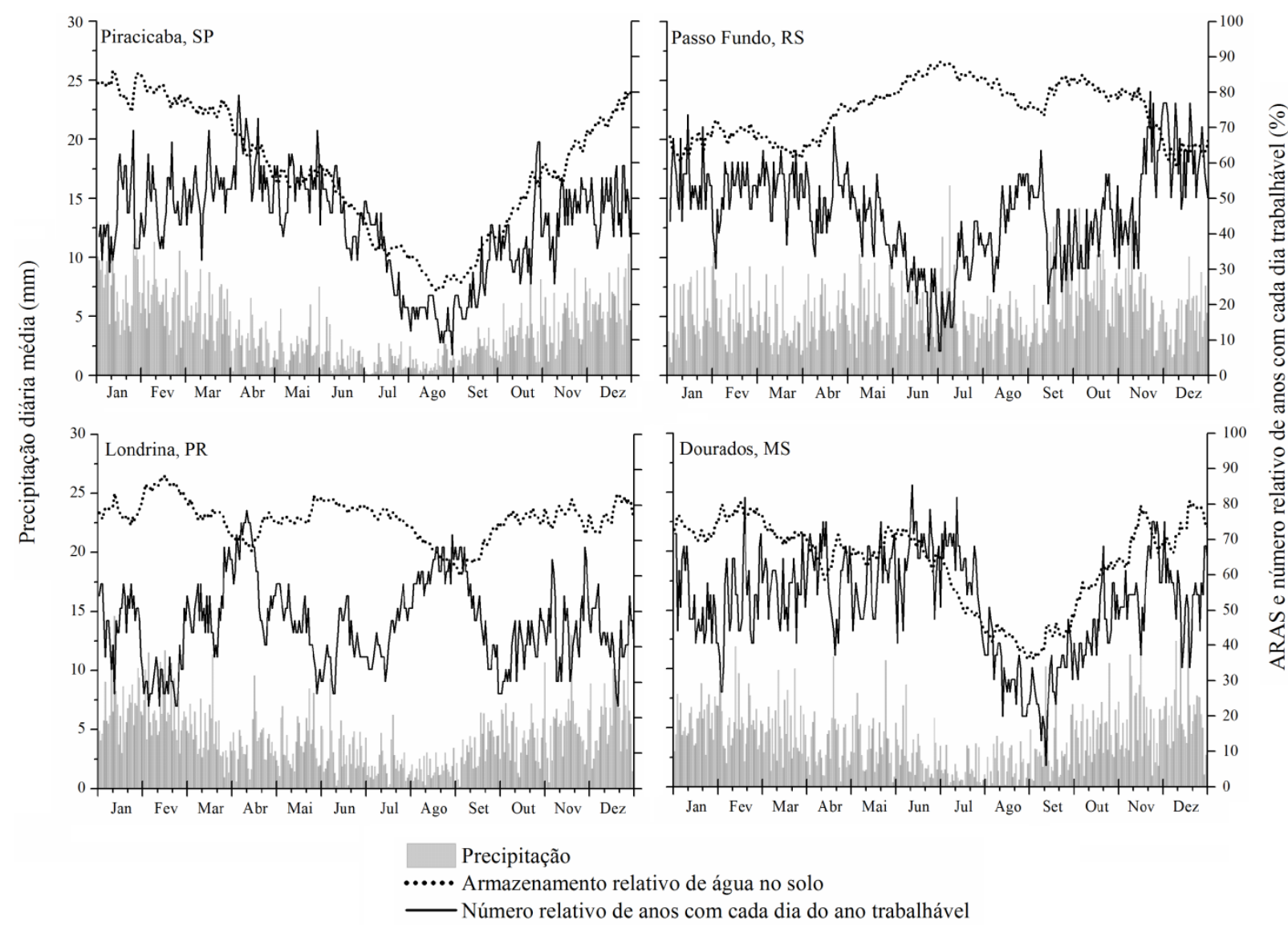

Figura 1. Variabilidade média anual da precipitação, do armazenamento relativo de água no solo (ARAS) e do número relativo de anos em que cada dia foi favorável às operações mecanizadas de manejo do solo (trabalhável) em Piracicaba, SP, Passo Fundo, RS, Londrina, PR e Dourados, MS.

De acordo com a Figura 1, percebe-se que em Piracicaba, SP, em Londrina, PR, e em Dourados, MS, a precipitação segue um padrão de distribuição sazonal bem definido ao longo do ano, apresentando as estações seca, de junho a agosto, e chuvosa, de setembro a maio. Assis e Villa Nova (1995), estudando a variabilidade anual da precipitação em Piracicaba, SP, concluíram que a média anual de chuva dos meses centrais do ano dessa localidade contribui com apenas $7 \%$ da precipitação média anual, sendo as condições hídricas do solo inapropriadas para o emprego de maquinário para o seu manejo durante esses meses. Assim, a partir do primeiro decêndio de janeiro até o segundo decêndio de agosto, a tendência da precipitação diária em Piracicaba, SP, Londrina, PR, e Dourados, MS, é decrescente atingindo valores mínimos no final desse período. Por outro lado, a partir do terceiro decêndio de agosto a precipitação diária apresenta tendência crescente até o final do ano, período em que 
frequentemente ocorrem chuvas diárias maiores do que $5 \mathrm{~mm}$. Esse padrão de distribuição anual da precipitação, com períodos do ano bem definidos correspondentes à estação seca e à estação chuvosa também foi observado por Blain et al. (2007), Marcuzzo et al. (2012) e Sampaio et al. (2007), respectivamente, nas regiões de Piracicaba, Dourados e Londrina. Por outro lado, a região de Passo Fundo, RS, não apresenta estação seca, já que a distribuição da precipitação é praticamente constante ao longo do ano, embora os meses de junho e julho sejam os mais chuvosos na região central do Rio Grande do Sul (Streck et al., 2009).

O padrão anual da variabilidade e da tendência do armazenamento relativo de água no solo (ARAS) em Piracicaba e em Dourados é semelhante à distribuição da precipitação nessas localidades, sendo que ocorrem elevados níveis de ARAS no início do ano, decrescendo até meados de setembro, quando o ARAS atinge níveis da ordem de $30 \%$ para ambos locais. Sendo assim, as condições de armazenamento de água no solo são inapropriadas para o emprego de máquinas para o preparo e manejo do solo. Devido a isso, nos meses secos dessas localidades (junho a setembro), a porcentagem em que cada dia foi favorável às operações de manejo do solo é muito baixa, atingindo níveis inferiores a $10 \%$ no terceiro decêndio de agosto em Piracicaba e no segundo decêndio de setembro em Dourados, sendo esses os períodos do ano menos indicados às operações de preparo e manejo do solo, apesar dos reduzidos níveis de chuva nessas regiões.

Em Londrina, com exceção de fevereiro, em que os níveis de ARAS estão bastante próximos à $\mathrm{CAD}$, devido às intensas precipitações acumuladas nessa época do ano, o ARAS é predominantemente favorável às operações de preparo e manejo do solo ao longo dos demais meses. Por isso, a condição de favorabilidade ao emprego de máquinas para o manejo de solo é mais dependente da chuva diária.

Ainda que apresentem características climáticas distintas ao longo do ano, as localidades de Passo Fundo e Piracicaba tem distribuição anual semelhante para o número relativo de anos em que cada dia foi considerado como trabalhável. Em Piracicaba, as probabilidades de dias trabalháveis decrescem a partir do primeiro decêndio de junho até o terceiro decêndio de agosto, devido aos baixos níveis de armazenamento de água no solo, enquanto que em Passo Fundo, para esse mesmo período, a baixa probabilidade de dias trabalháveis se deve ao fato dos níveis de armazenamento de água no solo permanecerem próximos à CAD ao longo do ano todo e à ocorrência frequente de chuvas diárias superiores a $5 \mathrm{~mm}$, o que inviabiliza as operações moto-mecanizadas para o preparo e o manejo do solo, principalmente durante os meses mencionados.

Por meio da avaliação do número de anos no período de 1980 a 2008 em que cada mês apresentou favorabilidade alta, média e baixa às operações moto-mecanizadas de preparo do solo em relação ao número de dias trabalháveis, foi possível classificar cada mês do ano de acordo com esses níveis, conforme apresentado na Tabela 1.

A partir da Tabela 1 é possível observar que em maio ocorrem as maiores frequências de anos com condições de solo e clima favoráveis às operações de manejo do solo em Piracicaba, sendo esse mês classificado como de alta favorabilidade para essas operações. O período de outubro a abril apresentou favorabilidade média às operações de manejo do solo, devido à tendência de aumento das chuvas e do armazenamento relativo de água no solo (Figura 1). Junho também apresentou favorabilidade média, entretanto, os níveis de precipitação e ARAS são baixos nesse período. Os meses de julho, agosto e setembro apresentaram maiores frequências de anos com baixa favorabilidade ao emprego de máquinas no preparo do solo, uma vez que os níveis de ARAS nesses meses estão abaixo de 40\% da CAD (Figura 1), potencializando a desagregação do solo e o risco de erosão. 
Tabela 1. Número de anos com "alta" ( $>20$ dias), "média" (11 a 20 dias) e "baixa" (< 11 dias) favorabilidade de dias trabalháveis em cada mês do ano nas localidades de Piracicaba, SP, Passo Fundo, RS, Londrina, PR e Dourados, MS.

\begin{tabular}{cccccccccccccc}
\hline \multirow{2}{*}{ Meses } & \multicolumn{3}{c}{ Piracicaba, SP } & \multicolumn{3}{c}{ Passo Fundo, RS } & \multicolumn{3}{c}{ Londrina, PR } & \multicolumn{3}{c}{ Dourados, MS } \\
\cline { 2 - 10 } & Baixa & Média & Alta & Baixa & Média & Alta & Baixa & Média & Alta & Baixa & Média & Alta \\
\hline Jan & 7 & 16 & 6 & 5 & 15 & 9 & 10 & 12 & 7 & 6 & 18 & 5 \\
Fev & 8 & 17 & 4 & 4 & 20 & 5 & 19 & 9 & 1 & 4 & 20 & 5 \\
Mar & 4 & 17 & 8 & 4 & 16 & 9 & 9 & 10 & 10 & 6 & 12 & 11 \\
Abr & 3 & 16 & 10 & 8 & 13 & 8 & 5 & 14 & 10 & 4 & 12 & 13 \\
Mai & 9 & 7 & 13 & 7 & 13 & 9 & 11 & 8 & 10 & 8 & 11 & 10 \\
Jun & 8 & 12 & 9 & 18 & 9 & 2 & 15 & 8 & 6 & 7 & 9 & 13 \\
Jul & 18 & 4 & 7 & 19 & 8 & 2 & 13 & 10 & 6 & 8 & 9 & 12 \\
Ago & 22 & 5 & 2 & 10 & 11 & 8 & 5 & 9 & 15 & 14 & 8 & 7 \\
Set & 18 & 9 & 2 & 13 & 13 & 3 & 11 & 10 & 8 & 20 & 7 & 2 \\
Out & 12 & 13 & 4 & 10 & 15 & 4 & 13 & 9 & 7 & 6 & 16 & 7 \\
Nov & 8 & 18 & 3 & 2 & 19 & 8 & 11 & 12 & 6 & 1 & 20 & 8 \\
Dez & 6 & 21 & 2 & 2 & 13 & 14 & 9 & 15 & 5 & 4 & 20 & 5 \\
\hline
\end{tabular}

Em Passo Fundo, nos períodos de janeiro a maio e de outubro a novembro predominam de 11 a 20 dias trabalháveis por mês (favorabilidade média), enquanto que os meses de junho e julho configuram-se como períodos de baixa favorabilidade ao emprego de máquinas para o manejo de solo devido aos elevados níveis de ARAS, frequentemente acima de $90 \%$ da CAD, e às chuvas normalmente acima de $5 \mathrm{~mm}$ (Figura 1). Setembro apresentou mesma frequência quanto ao número de anos com favorabilidade baixa e média, portanto, é um mês que apresenta risco de compactação do solo, devido aos elevados níveis de ARAS, principalmente no primeiro decêndio desse mês (Figura 1). Por outro lado, dezembro é um mês com elevado potencial para as operações de preparo moto-mecanizado do solo, pois foi elevada a frequência dos anos que apresentaram, pelo menos, 11 dias favoráveis para tais atividades.

Em Londrina, foi possível observar que o mês de agosto apresenta alta favorabilidade às operações de manejo do solo, com mais de 20 dias favoráveis. Além disso, nos dois primeiros decêndios de abril (Figura1) houve a ocorrência de média a alta favorabilidade para as operações moto-mecanizadas. Os meses de fevereiro, junho e julho, devido às chuvas diárias frequentemente superiores a $10 \mathrm{~mm}$ e níveis de $\mathrm{ARAS}$ próximos à $\mathrm{CAD}$, tem baixa favorabilidade às operações de manejo do solo, não sendo indicados para essas atividades (Figura 1). Os meses de setembro a janeiro são de baixa a média favorabilidade, portanto, deve-se ter maior atenção às condições meteorológicas vigentes para a realização do manejo e preparo do solo, para que seja possível minimizar os riscos de desestruturação ou compactação do solo.

Dourados apresenta em janeiro e fevereiro favorabilidade média, havendo pelo menos 10 dias favoráveis por mês ao manejo do solo. De março a junho, a quantidade de anos com condições de favorabilidade alta vai aumentou gradativamente, devido às precipitações diárias 
serem decrescentes até metade do ano, enquanto que em agosto e setembro ocorrem menos de 11 dias favoráveis às operações moto-mecanizadas, o que se deve aos reduzidos níveis de conteúdo de água no solo (Figura 1).

Por meio da análise das probabilidades simples, das probabilidades condicionais e das probabilidades de ocorrência de dias consecutivos "favoráveis" ao emprego de mecanização no preparo e manejo do solo é possível identificar os decêndios mais aptos para tais atividades, assim como os decêndios nos quais se devem evitá-las, devido ao risco associado à desestruturação, erosão e compactação do solo, ocasionados pelo emprego de máquinas em condições inapropriadas de chuva e de armazenamento de água no solo. Da mesma maneira, a estimativa das probabilidades de sequência de dias favoráveis é importante porque, em nível operacional e de planejamento agrícola, devem-se considerar os períodos do ano mais apropriados para a realização das operações mecanizadas de manejo do solo, assim como o número de dias que cada operação necessita para ser concluída. A Tabela 2 apresenta essas probabilidades ao longo do ano em Piracicaba, SP.

Em Piracicaba (Tabela 2), a P(F) variou de $66,6 \%$, no primeiro decêndio de abril, a $14,1 \%$, no terceiro decêndio de agosto, enquanto que a média anual da $\mathrm{P}(\mathrm{F})$ é de $43,1 \%$ e seu desvio padrão de $12,7 \%$. No período mais adequado ao emprego de maquinário para o manejo do solo (primeiro decêndio de abril), as probabilidades condicionais $\mathrm{P}(\mathrm{F} / \mathrm{F})$ e $\mathrm{P}(\mathrm{NF} / \mathrm{NF})$ foram iguais a 74,4 e 46,9\%, respectivamente, indicando forte persistência entre dias favoráveis consecutivos nessa época do ano. Por outro lado, no decêndio menos favorável (terceiro decêndio de agosto), as probabilidades condicionais $\mathrm{P}(\mathrm{F} / \mathrm{F})$ e $\mathrm{P}(\mathrm{NF} / \mathrm{NF})$ foram iguais a 19,1 e $90,8 \%$, respectivamente, indicando forte relação entre dias consecutivos não favoráveis ao emprego de máquinas para o preparo do solo, uma vez que nesse decêndio os níveis de chuva e conteúdo de água no solo são muito baixos inviabilizando o período para essas operações. Erthal e Sentelhas (1995) avaliaram a sequência de dias secos e os níveis de armazenamento relativo de água no solo entre os meses de outubro e março em Campinas, SP, obtendo níveis probabilísticos semelhantes aos obtidos neste trabalho para a região de Piracicaba, que estão a cerca de $60 \mathrm{~km}$ uma da outra.

Como exemplo da importância de informações sobre a probabilidade das sequências de dias favoráveis a uma determinada operação agrícola de manejo do solo, caso em Piracicaba, SP, uma operação exija cinco dias consecutivos favoráveis para ser concluída em abril, esta deverá ser programada para o primeiro decêndio, porque a probabilidade é de $20,4 \%$ e não para o terceiro decêndio do mês, quando tal probabilidade é de apenas 7,3\%.

Em Passo Fundo, RS, a distribuição anual das probabilidades simples, das probabilidades condicionais e da probabilidade de dias consecutivos favoráveis à mecanização e preparo do solo são apresentadas na Tabela 3, na qual se observa que a $\mathrm{P}(\mathrm{F})$ variou de $69,7 \%$, no primeiro decêndio de dezembro, a 19,0\%, no primeiro decêndio de julho, sendo que nos períodos menos favoráveis, além de elevados níveis diários de chuva, também ocorreram armazenamentos relativos de água no solo superior a $90 \%$ da CAD, tornando os meses de junho e julho não recomendados para as operações de manejo e preparo de solo, devido ao risco de compactação do solo. A P(F) anual média em Passo Fundo é de 47,6\%, com um desvio padrão de $11,9 \%$. O primeiro decêndio de julho apresenta baixa probabilidade de persistência de dois dias consecutivos favoráveis $(\mathrm{P}(\mathrm{F} / \mathrm{F}))$ às operações de preparo do solo $(14,4 \%)$, enquanto que no primeiro decêndio de dezembro, o mais indicado para as operações ao longo do ano, essa probabilidade é de $68,2 \%$. A probabilidade condicional de ocorrência de dias não favoráveis $\mathrm{P}(\mathrm{NF} / \mathrm{NF})$ no primeiro decêndio de julho foi elevada $(70,1 \%)$, já que os níveis de ARAS são maiores que $90 \%$ em diversos dias naquele período, enquanto que no primeiro decêndio de dezembro essa probabilidade é de apenas 33,3\%. 
Tabela 2. Probabilidades simples, probabilidades condicionais e probabilidades de dias consecutivos favoráveis ao preparo mecanizado do solo e suas respectivas probabilidades média e desvio padrão (DP, em \%) em cada decêndio do ano em Piracicaba, SP.

\begin{tabular}{|c|c|c|c|c|c|c|c|c|c|c|c|c|c|c|c|c|}
\hline \multirow{2}{*}{ Decêndios } & \multicolumn{6}{|c|}{ Probabilidades simples e condicionais (\%) } & \multicolumn{10}{|c|}{ Probabilidades de dias consecutivos favoráveis (\%) } \\
\hline & $\mathrm{P}(\mathrm{F})$ & $\mathrm{P}(\mathrm{NF})$ & $\mathrm{P}(\mathrm{NF} / \mathrm{F})$ & $\mathrm{P}(\mathrm{F} / \mathrm{F})$ & $\mathrm{P}(\mathrm{F} / \mathrm{NF})$ & $\mathrm{P}(\mathrm{NF} / \mathrm{NF})$ & $\mathrm{P}(1)$ & $\mathrm{P}(2)$ & $\mathrm{P}(3)$ & $\mathrm{P}(4)$ & $\mathrm{P}(5)$ & $\mathrm{P}(6)$ & $\mathrm{P}(7)$ & $\mathrm{P}(8)$ & $\mathrm{P}(9)$ & $\mathrm{P}(10)$ \\
\hline Jan_1 & 39,0 & 61,0 & 38,5 & 61,5 & 27,0 & 73,0 & 39,0 & 24,0 & 14,7 & 9,1 & 5,6 & 3,4 & 2,1 & 1,3 & 0,8 & 0,5 \\
\hline Jan_2 & 50,7 & 49,3 & 38,1 & 61,9 & 26,8 & 73,2 & 50,7 & 31,4 & 19,4 & 12,0 & 7,4 & 4,6 & 2,8 & 1,8 & 1,1 & 0,7 \\
\hline Jan_3 & 46,1 & 53,9 & 39,3 & 60,7 & 36,8 & 63,2 & 46,1 & 28,0 & 17,0 & 10,3 & 6,2 & 3,8 & 2,3 & 1,4 & 0,8 & 0,5 \\
\hline Fev_1 & 50,3 & 49,7 & 40,5 & 59,5 & 40,5 & 59,5 & 50,3 & 29,9 & 17,8 & 10,6 & 6,3 & 3,7 & 2,2 & 1,3 & 0,8 & 0,5 \\
\hline $\mathrm{Fev} \_2$ & 48,6 & 51,4 & 42,2 & 57,8 & 35,8 & 64,2 & 48,6 & 28,1 & 16,3 & 9,4 & 5,4 & 3,1 & 1,8 & 1,1 & 0,6 & 0,4 \\
\hline Fev_3 & 48,7 & 51,3 & 38,7 & 61,3 & 36,2 & 63,8 & 48,7 & 29,9 & 18,3 & 11,2 & 6,9 & 4,2 & 2,6 & 1,6 & 1,0 & 0,6 \\
\hline Mar_1 & 50,3 & 49,7 & 36,3 & 63,7 & 37,9 & 62,1 & 50,3 & 32,1 & 20,4 & 13,0 & 8,3 & 5,3 & 3,4 & 2,1 & 1,4 & 0,9 \\
\hline Mar_2 & 53,4 & 46,6 & 33,3 & 66,7 & 37,3 & 62,7 & 53,4 & 35,7 & 23,8 & 15,9 & 10,6 & 7,1 & 4,7 & 3,2 & 2,1 & 1,4 \\
\hline Mar_3 & 52,7 & 47,3 & 30,1 & 69,9 & 38,1 & 61,9 & 52,7 & 36,8 & 25,8 & 18,0 & 12,6 & 8,8 & 6,2 & 4,3 & 3,0 & 2,1 \\
\hline Abr_1 & 66,6 & 33,4 & 25,6 & 74,4 & 53,1 & 46,9 & 66,6 & 49,5 & 36,9 & 27,5 & 20,4 & 15,2 & 11,3 & 8,4 & 6,3 & 4,7 \\
\hline Abr_2 & 59,0 & 41,0 & 29,3 & 70,7 & 51,9 & 48,1 & 59,0 & 41,7 & 29,4 & 20,8 & 14,7 & 10,4 & 7,3 & 5,2 & 3,7 & 2,6 \\
\hline Abr_3 & 53,4 & 46,6 & 39,2 & 60,8 & 43,9 & 56,1 & 53,4 & 32,5 & 19,8 & 12,0 & 7,3 & 4,4 & 2,7 & 1,6 & 1,0 & 0,6 \\
\hline Mai_1 & 51,0 & 49,0 & 39,7 & 60,3 & 47,0 & 53,0 & 51,0 & 30,8 & 18,6 & 11,2 & 6,8 & 4,1 & 2,5 & 1,5 & 0,9 & 0,5 \\
\hline Mai_2 & 54,8 & 45,2 & 39,9 & 60,1 & 52,5 & 47,5 & 54,8 & 32,9 & 19,8 & 11,9 & 7,1 & 4,3 & 2,6 & 1,5 & 0,9 & 0,6 \\
\hline Mai_3 & 53,9 & 46,1 & 37,8 & 62,2 & 43,6 & 56,4 & 53,9 & 33,6 & 20,9 & 13,0 & 8,1 & 5,0 & 3,1 & 1,9 & 1,2 & 0,8 \\
\hline Jun_1 & 52,4 & 47,6 & 35,4 & 64,6 & 40,9 & 59,1 & 52,4 & 33,9 & 21,9 & 14,1 & 9,1 & 5,9 & 3,8 & 2,5 & 1,6 & 1,0 \\
\hline Jun_2 & 42,8 & 57,2 & 40,0 & 60,0 & 28,8 & 71,2 & 42,8 & 25,6 & 15,4 & 9,2 & 5,5 & 3,3 & 2,0 & 1,2 & 0,7 & 0,4 \\
\hline Jun_3 & 44,5 & 55,5 & 48,1 & 51,9 & 30,7 & 69,3 & 44,5 & 23,1 & 12,0 & 6,2 & 3,2 & 1,7 & 0,9 & 0,5 & 0,2 & 0,1 \\
\hline Jul_1 & 44,5 & 55,5 & 47,8 & 52,2 & 41,3 & 58,7 & 44,5 & 23,2 & 12,1 & 6,3 & 3,3 & 1,7 & 0,9 & 0,5 & 0,2 & 0,1 \\
\hline Jul_2 & 32,1 & 67,9 & 60,3 & 39,7 & 24,6 & 75,4 & 32,1 & 12,7 & 5,1 & 2,0 & 0,8 & 0,3 & 0,1 & 0,1 & 0,0 & 0,0 \\
\hline Jul_3 & 21,6 & 78,4 & 64,2 & 35,8 & 12,0 & 88,0 & 21,6 & 7,8 & 2,8 & 1,0 & 0,4 & 0,1 & 0,0 & 0,0 & 0,0 & 0,0 \\
\hline Ago_1 & 19,7 & 80,3 & 80,5 & 19,5 & 17,9 & 82,1 & 19,7 & 3,8 & 0,7 & 0,1 & 0,0 & 0,0 & 0,0 & 0,0 & 0,0 & 0,0 \\
\hline Ago_2 & 17,9 & 82,1 & 77,6 & 22,4 & 14,4 & 85,6 & 17,9 & 4,0 & 0,9 & 0,2 & 0,0 & 0,0 & 0,0 & 0,0 & 0,0 & 0,0 \\
\hline Ago_3 & 14,1 & 85,9 & 80,9 & 19,1 & 9,2 & 90,8 & 14,1 & 2,7 & 0,5 & 0,1 & 0,0 & 0,0 & 0,0 & 0,0 & 0,0 & 0,0 \\
\hline Set_1 & 18,3 & 81,7 & 76,3 & 23,7 & 16,3 & 83,7 & 18,3 & 4,3 & 1,0 & 0,2 & 0,1 & 0,0 & 0,0 & 0,0 & 0,0 & 0,0 \\
\hline Set_2 & 26,2 & 73,8 & 66,1 & 33,9 & 17,9 & 82,1 & 26,2 & 8,9 & 3,0 & 1,0 & 0,3 & 0,1 & 0,0 & 0,0 & 0,0 & 0,0 \\
\hline Set_3 & 37,9 & 62,1 & 56,2 & 43,8 & 25,5 & 74,5 & 37,9 & 16,6 & 7,3 & 3,2 & 1,4 & 0,6 & 0,3 & 0,1 & 0,1 & 0,0 \\
\hline Out_1 & 35,9 & 64,1 & 57,4 & 42,6 & 32,7 & 67,3 & 35,9 & 15,3 & 6,5 & 2,8 & 1,2 & 0,5 & 0,2 & 0,1 & 0,0 & 0,0 \\
\hline Out_2 & 32,8 & 67,2 & 60,0 & 40,0 & 29,5 & 70,5 & 32,8 & 13,1 & 5,2 & 2,1 & 0,8 & 0,3 & 0,1 & 0,1 & 0,0 & 0,0 \\
\hline Out_3 & 48,6 & 51,4 & 29,5 & 70,5 & 27,5 & 72,5 & 48,6 & 34,2 & 24,1 & 17,0 & 12,0 & 8,4 & 6,0 & 4,2 & 3,0 & 2,1 \\
\hline Nov_1 & 42,8 & 57,2 & 50,1 & 49,9 & 38,0 & 62,0 & 42,8 & 21,3 & 10,6 & 5,3 & 2,7 & 1,3 & 0,7 & 0,3 & 0,2 & 0,1 \\
\hline Nov_2 & 45,5 & 54,5 & 39,3 & 60,7 & 35,6 & 64,4 & 45,5 & 27,6 & 16,8 & 10,2 & 6,2 & 3,8 & 2,3 & 1,4 & 0,8 & 0,5 \\
\hline Nov_3 & 51,0 & 49,0 & 35,1 & 64,9 & 40,1 & 59,9 & 51,0 & 33,1 & 21,5 & 13,9 & 9,0 & 5,9 & 3,8 & 2,5 & 1,6 & 1,0 \\
\hline Dez_1 & 45,9 & 54,1 & 43,1 & 56,9 & 38,3 & 61,7 & 45,9 & 26,1 & 14,9 & 8,5 & 4,8 & 2,7 & 1,6 & 0,9 & 0,5 & 0,3 \\
\hline Dez_2 & 49,3 & 50,7 & 36,6 & 63,4 & 36,1 & 63,9 & 49,3 & 31,3 & 19,8 & 12,6 & 8,0 & 5,1 & 3,2 & 2,0 & 1,3 & 0,8 \\
\hline Dez_3 & 48,3 & 51,7 & 38,7 & 61,3 & 38,4 & 61,6 & 48,3 & 29,6 & 18,2 & 11,1 & 6,8 & 4,2 & 2,6 & 1,6 & 1,0 & 0,6 \\
\hline Média & 43,1 & 56,9 & 46,4 & 53,6 & 33,5 & 66,5 & 43,1 & 24,9 & 15,0 & 9,3 & 5,8 & 3,7 & 2,4 & 1,6 & 1,0 & 0,7 \\
\hline DP & 12,7 & 12,7 & 15,2 & 15,2 & 11,2 & 11,2 & 12,7 & 11,5 & 8,8 & 6,4 & 4,6 & 3,4 & 2,4 & 1,8 & 1,3 & 0,9 \\
\hline
\end{tabular}


Com base nas probabilidades de dias consecutivos favoráveis ao manejo do solo, na localidade de Passo Fundo, por exemplo, devem-se planejar as operações de preparo do solo, que necessitem de pelo menos cinco dias consecutivos para a sua execução, a partir do terceiro decêndio de novembro até o terceiro decêndio de dezembro, já que a probabilidade de haver cinco dias favoráveis é da ordem de 10\%. Mesmo assim, deve-se ter cuidado no planejamento dessas atividades porque as probabilidades condicionais $\mathrm{P}(\mathrm{NF} / \mathrm{F})$ e $\mathrm{P}(\mathrm{NF} / \mathrm{NF})$ ultrapassam $85 \%$ em alguns decêndios, dificultando as operações de manejo do solo que exijam períodos mais prolongados.

Em Londrina, PR (Tabela 4), ocorrem dois períodos ao longo do ano com elevada probabilidade de ocorrência de dias favoráveis às operações moto-mecanizadas. $\mathrm{O}$ primeiro decêndio de abril apresenta $\mathrm{P}(\mathrm{F})$ igual a $70,7 \%$ e o primeiro e segundo decêndios de agosto, com média de favorabilidade igual a $65 \%$. A média e o desvio padrão anuais são respectivamente iguais a $47,4 \%$ e $9,9 \%$. O primeiro e segundo decêndios de fevereiro são os decêndios menos indicados para as operações de manejo do solo, porque apresentam probabilidades de ocorrência de 30,3 e $31 \%$, respectivamente, devido ao ARAS nesse período estar próximo à $\mathrm{CAD}$ e à ocorrência de chuvas diárias frequentemente superiores aos $5 \mathrm{~mm}$ (Figura 1).

Os resultados obtidos neste trabalho para a região de Londrina, PR, concordam parcialmente com os apresentados por Ataíde et al. (2012). Esses autores identificaram o mês de agosto com probabilidades de dias trabalháveis superiores a $85 \%$, devido ao fato de não considerarem o limite inferior de armazenamento de água no solo ( $40 \%$ da CAD). Além disso, o mês de agosto apresenta $\mathrm{P}(\mathrm{F} / \mathrm{F})$ máxima de $15,5 \%$ no segundo e terceiro decêndios e por isso a probabilidade de três ou mais dias aptos ao emprego de máquinas no manejo do solo é praticamente nula. Por outro lado, o primeiro decêndio de abril além de apresentar $\mathrm{P}(\mathrm{F})$ de $70,7 \%$, tem persistência de dias favoráveis consecutivos com probabilidade elevada $(\mathrm{P}(\mathrm{F} / \mathrm{F})=75,7 \%)$, sendo, portanto, o período mais favorável ao longo do ano para as operações moto-mecanizadas do solo que demandem maior sequência consecutiva de dias favoráveis.

Os resultados obtidos para Dourados, MS, são corroborados pelos obtidos por Fietz et al. (2001), os quais identificaram a ocorrência de maiores déficits hídricos entre agosto e setembro, quando a favorabilidade ao emprego de máquinas para o manejo de solo (Tabela 1) é baixa devido aos reduzidos níveis de água armazenada no solo, conforme apresentado na Figura 1. As variabilidades decendiais das probabilidades simples, condicionais e da sequência de dias trabalháveis para Dourados (Tabela 5) mostram que os períodos com maior $\mathrm{P}(\mathrm{F})$ são o segundo decêndio de junho $(63,8 \%)$ e o segundo decêndio de novembro $(62,4 \%)$. Embora esses períodos tenham $\mathrm{P}(\mathrm{F})$ semelhantes, o segundo decêndio de novembro é mais adequado às operações mecanizadas porque a $\mathrm{P}(\mathrm{F} / \mathrm{F})$ nesse período é igual a $68,5 \%$, enquanto que no segundo decêndio de junho esse valor é menor, igual a 50,5\%.

Sendo assim, para Dourados, as operações moto-mecanizadas que necessitem ser concluídas, por exemplo, em três dias consecutivos, devem ser feitas no segundo decêndio de novembro que é quando há a maior probabilidade de ocorrência de tal sequencia de dias $(29,3 \%)$. Essa probabilidade é reduzida praticamente pela metade caso as atividades sejam programadas para o segundo decêndio de junho. Da mesma maneira, operações de manejo do solo que exijam pelo menos seis dias consecutivos de favorabilidade não são indicadas para essa localidade devido aos baixos níveis de probabilidade $(<10 \%)$ ao longo de todo o ano (Tabela 5). 
Tabela 3. Probabilidades simples, probabilidades condicionais e probabilidades de dias consecutivos favoráveis ao preparo mecanizado do solo e suas respectivas probabilidades média e desvio padrão (DP) em cada decêndio do ano em Passo Fundo, RS.

\begin{tabular}{|c|c|c|c|c|c|c|c|c|c|c|c|c|c|c|c|c|}
\hline \multirow{2}{*}{ Decêndios } & \multicolumn{6}{|c|}{ Probabilidades simples e condicionais (\%) } & \multicolumn{10}{|c|}{ Probabilidades de dias consecutivos favoráveis (\%) } \\
\hline & $\mathrm{P}(\mathrm{F})$ & $\mathrm{P}(\mathrm{NF})$ & $\mathrm{P}(\mathrm{NF} / \mathrm{F})$ & $\mathrm{P}(\mathrm{F} / \mathrm{F})$ & $\mathrm{P}(\mathrm{F} / \mathrm{NF})$ & $\mathrm{P}(\mathrm{NF} / \mathrm{NF})$ & $\mathrm{P}(1)$ & $\mathrm{P}(2)$ & $\mathrm{P}(3)$ & $\mathrm{P}(4)$ & $\mathrm{P}(5)$ & $\mathrm{P}(6)$ & $\mathrm{P}(7)$ & $\mathrm{P}(8)$ & $\mathrm{P}(9)$ & $\mathrm{P}(10)$ \\
\hline Jan_1 & 54,5 & 45,5 & 38,3 & 61,7 & 45,6 & 54,4 & 54,5 & 33,6 & 20,8 & 12,8 & 7,9 & 4,9 & 3,0 & 1,9 & 1,1 & 0,7 \\
\hline Jan_2 & 56,6 & 43,4 & 43,8 & 56,2 & 57,0 & 43,0 & 56,6 & 31,8 & 17,8 & 10,0 & 5,6 & 3,2 & 1,8 & 1,0 & 0,6 & 0,3 \\
\hline Jan_3 & 55,5 & 44,5 & 39,3 & 60,7 & 43,2 & 56,8 & 55,5 & 33,7 & 20,5 & 12,4 & 7,5 & 4,6 & 2,8 & 1,7 & 1,0 & 0,6 \\
\hline Fev_1 & 52,4 & 47,6 & 47,3 & 52,7 & 46,5 & 53,5 & 52,4 & 27,6 & 14,5 & 7,7 & 4,0 & 2,1 & 1,1 & 0,6 & 0,3 & 0,2 \\
\hline Fev_2 & 59,7 & 40,3 & 44,5 & 55,5 & 51,6 & 48,4 & 59,7 & 33,1 & 18,4 & 10,2 & 5,7 & 3,2 & 1,8 & 1,0 & 0,5 & 0,3 \\
\hline Fev_3 & 56,3 & 43,7 & 32,8 & 67,2 & 59,2 & 40,8 & 56,3 & 37,9 & 25,4 & 17,1 & 11,5 & 7,7 & 5,2 & 3,5 & 2,3 & 1,6 \\
\hline Mar_1 & 54,1 & 45,9 & 40,2 & 59,8 & 49,5 & 50,5 & 54,1 & 32,4 & 19,4 & 11,6 & 6,9 & 4,2 & 2,5 & 1,5 & 0,9 & 0,5 \\
\hline Mar_2 & 57,2 & 42,8 & 38,5 & 61,5 & 49,7 & 50,3 & 57,2 & 35,2 & 21,7 & 13,3 & 8,2 & 5,0 & 3,1 & 1,9 & 1,2 & 0,7 \\
\hline Mar_3 & 50,8 & 49,2 & 38,9 & 61,1 & 42,5 & 57,5 & 50,8 & 31,0 & 18,9 & 11,6 & 7,1 & 4,3 & 2,6 & 1,6 & 1,0 & 0,6 \\
\hline Abr_1 & 50,3 & 49,7 & 41,9 & 58,1 & 54,6 & 45,4 & 50,3 & 29,3 & 17,0 & 9,9 & 5,8 & 3,3 & 1,9 & 1,1 & 0,7 & 0,4 \\
\hline Abr_2 & 49,0 & 51,0 & 45,6 & 54,4 & 38,3 & 61,7 & 49,0 & 26,7 & 14,5 & 7,9 & 4,3 & 2,3 & 1,3 & 0,7 & 0,4 & 0,2 \\
\hline Abr_3 & 56,6 & 43,4 & 47,7 & 52,3 & 53,3 & 46,7 & 56,6 & 29,6 & 15,5 & 8,1 & 4,2 & 2,2 & 1,2 & 0,6 & 0,3 & 0,2 \\
\hline Mai_1 & 52,8 & 47,2 & 55,2 & 44,8 & 42,7 & 57,3 & 52,8 & 23,7 & 10,6 & 4,8 & 2,1 & 1,0 & 0,4 & 0,2 & 0,1 & 0,0 \\
\hline Mai_2 & 50,0 & 50,0 & 53,4 & 46,6 & 44,9 & 55,1 & 50,0 & 23,3 & 10,8 & 5,0 & 2,3 & 1,1 & 0,5 & 0,2 & 0,1 & 0,1 \\
\hline Mai_3 & 44,2 & 55,8 & 45,2 & 54,8 & 34,2 & 65,8 & 44,2 & 24,2 & 13,3 & 7,3 & 4,0 & 2,2 & 1,2 & 0,7 & 0,4 & 0,2 \\
\hline Jun_1 & 40,3 & 59,7 & 59,9 & 40,1 & 44,3 & 55,7 & 40,3 & 16,2 & 6,5 & 2,6 & 1,0 & 0,4 & 0,2 & 0,1 & 0,0 & 0,0 \\
\hline Jun_2 & 32,8 & 67,2 & 69,5 & 30,5 & 22,5 & 77,5 & 32,8 & 10,0 & 3,1 & 0,9 & 0,3 & 0,1 & 0,0 & 0,0 & 0,0 & 0,0 \\
\hline Jun_3 & 20,3 & 79,7 & 78,2 & 21,8 & 27,8 & 72,2 & 20,3 & 4,4 & 1,0 & 0,2 & 0,0 & 0,0 & 0,0 & 0,0 & 0,0 & 0,0 \\
\hline Jul_1 & 19,0 & 81,0 & 85,6 & 14,4 & 29,9 & 70,1 & 19,0 & 2,7 & 0,4 & 0,1 & 0,0 & 0,0 & 0,0 & 0,0 & 0,0 & 0,0 \\
\hline Jul_2 & 30,7 & 69,3 & 78,5 & 21,5 & 14,8 & 85,2 & 30,7 & 6,6 & 1,4 & 0,3 & 0,1 & 0,0 & 0,0 & 0,0 & 0,0 & 0,0 \\
\hline Jul_3 & 34,8 & 65,2 & 81,3 & 18,7 & 24,8 & 75,2 & 34,8 & 6,5 & 1,2 & 0,2 & 0,0 & 0,0 & 0,0 & 0,0 & 0,0 & 0,0 \\
\hline Ago_1 & 33,8 & 66,2 & 87,1 & 12,9 & 34,9 & 65,1 & 33,8 & 4,4 & 0,6 & 0,1 & 0,0 & 0,0 & 0,0 & 0,0 & 0,0 & 0,0 \\
\hline Ago_2 & 48,3 & 51,7 & 84,8 & 15,2 & 38,8 & 61,2 & 48,3 & 7,4 & 1,1 & 0,2 & 0,0 & 0,0 & 0,0 & 0,0 & 0,0 & 0,0 \\
\hline Ago_3 & 55,5 & 44,5 & 79,3 & 20,7 & 36,9 & 63,1 & 55,5 & 11,5 & 2,4 & 0,5 & 0,1 & 0,0 & 0,0 & 0,0 & 0,0 & 0,0 \\
\hline Set_1 & 50,3 & 49,7 & 77,3 & 22,7 & 37,9 & 62,1 & 50,3 & 11,4 & 2,6 & 0,6 & 0,1 & 0,0 & 0,0 & 0,0 & 0,0 & 0,0 \\
\hline Set_2 & 34,1 & 65,9 & 77,4 & 22,6 & 25,9 & 74,1 & 34,1 & 7,7 & 1,7 & 0,4 & 0,1 & 0,0 & 0,0 & 0,0 & 0,0 & 0,0 \\
\hline Set_3 & 37,2 & 62,8 & 71,9 & 28,1 & 33,8 & 66,2 & 37,2 & 10,4 & 2,9 & 0,8 & 0,2 & 0,1 & 0,0 & 0,0 & 0,0 & 0,0 \\
\hline Out_1 & 37,2 & 62,8 & 70,7 & 29,3 & 30,7 & 69,3 & 37,2 & 10,9 & 3,2 & 0,9 & 0,3 & 0,1 & 0,0 & 0,0 & 0,0 & 0,0 \\
\hline Out_2 & 40,3 & 59,7 & 58,4 & 41,6 & 29,8 & 70,2 & 40,3 & 16,8 & 7,0 & 2,9 & 1,2 & 0,5 & 0,2 & 0,1 & 0,0 & 0,0 \\
\hline Out_3 & 46,7 & 53,3 & 44,5 & 55,5 & 35,6 & 64,4 & 46,7 & 25,9 & 14,4 & 8,0 & 4,4 & 2,5 & 1,4 & 0,8 & 0,4 & 0,2 \\
\hline Nov_1 & 40,3 & 59,7 & 65,1 & 34,9 & 30,8 & 69,2 & 40,3 & 14,1 & 4,9 & 1,7 & 0,6 & 0,2 & 0,1 & 0,0 & 0,0 & 0,0 \\
\hline Nov_2 & 55,2 & 44,8 & 39,3 & 60,7 & 29,8 & 70,2 & 55,2 & 33,5 & 20,4 & 12,4 & 7,5 & 4,6 & 2,8 & 1,7 & 1,0 & 0,6 \\
\hline Nov_3 & 66,2 & 33,8 & 36,1 & 63,9 & 57,5 & 42,5 & 66,2 & 42,3 & 27,0 & 17,3 & 11,0 & 7,1 & 4,5 & 2,9 & 1,8 & 1,2 \\
\hline Dez_1 & 69,7 & 30,3 & 31,8 & 68,2 & 66,7 & 33,3 & 69,7 & 47,5 & 32,4 & 22,1 & 15,1 & 10,3 & 7,0 & 4,8 & 3,3 & 2,2 \\
\hline Dez_2 & 59,7 & 40,3 & 31,6 & 68,4 & 52,1 & 47,9 & 59,7 & 40,8 & 27,9 & 19,1 & 13,1 & 8,9 & 6,1 & 4,2 & 2,9 & 2,0 \\
\hline Dez_3 & 59,9 & 40,1 & 31,4 & 68,6 & 46,9 & 53,1 & 59,9 & 41,1 & 28,2 & 19,4 & 13,3 & 9,1 & 6,3 & 4,3 & 2,9 & 2,0 \\
\hline Média & 47,6 & 52,4 & 55,3 & 44,7 & 40,7 & 59,3 & 47,6 & 22,9 & 12,5 & 7,2 & 4,3 & 2,6 & 1,6 & 1,0 & 0,6 & 0,4 \\
\hline DP & 11,9 & 11,9 & 18,5 & 18,5 & 11,8 & 11,8 & 11,9 & 12,9 & 9,6 & 6,6 & 4,5 & 3,0 & 2,0 & 1,4 & 0,9 & 0,6 \\
\hline
\end{tabular}


Tabela 4. Probabilidades simples, probabilidades condicionais e probabilidades de dias consecutivos favoráveis ao preparo mecanizado do solo e suas respectivas probabilidades média e desvio padrão (DP) em cada decêndio do ano em Londrina, PR.

\begin{tabular}{|c|c|c|c|c|c|c|c|c|c|c|c|c|c|c|c|c|}
\hline \multirow{2}{*}{ Decêndios } & \multicolumn{6}{|c|}{ Probabilidades simples e condicionais (\%) } & \multicolumn{10}{|c|}{ Probabilidades de dias consecutivos favoráveis (\%) } \\
\hline & $\mathrm{P}(\mathrm{F})$ & $\mathrm{P}(\mathrm{NF})$ & $\mathrm{P}(\mathrm{NF} / \mathrm{F})$ & $\mathrm{P}(\mathrm{F} / \mathrm{F})$ & $\mathrm{P}(\mathrm{F} / \mathrm{NF})$ & $\mathrm{P}(\mathrm{NF} / \mathrm{NF})$ & $\mathrm{P}(1)$ & $\mathrm{P}(2)$ & $\mathrm{P}(3)$ & $\mathrm{P}(4)$ & $\mathrm{P}(5)$ & $\mathrm{P}(6)$ & $\mathrm{P}(7)$ & $\mathrm{P}(8)$ & $\mathrm{P}(9)$ & $\mathrm{P}(10)$ \\
\hline Jan_1 & 47,2 & 52,8 & 35,3 & 64,7 & 31,8 & 68,2 & 47,2 & 30,5 & 19,7 & 12,8 & 8,3 & 5,3 & 3,4 & 2,2 & 1,4 & 0,9 \\
\hline Jan_2 & 48,3 & 51,7 & 47,9 & 52,1 & 37,9 & 62,1 & 48,3 & 25,2 & 13,1 & 6,8 & 3,6 & 1,9 & 1,0 & 0,5 & 0,3 & 0,1 \\
\hline Jan_3 & 47,0 & 53,0 & 36,5 & 63,5 & 35,8 & 64,2 & 47,0 & 29,9 & 19,0 & 12,1 & 7,7 & 4,9 & 3,1 & 2,0 & 1,2 & 0,8 \\
\hline Fev_1 & 30,3 & 69,7 & 56,2 & 43,8 & 24,3 & 75,7 & 30,3 & 13,3 & 5,8 & 2,6 & 1,1 & 0,5 & 0,2 & 0,1 & 0,0 & 0,0 \\
\hline Fev_2 & 31,0 & 69,0 & 61,1 & 38,9 & 24,3 & 75,7 & 31,0 & 12,1 & 4,7 & 1,8 & 0,7 & 0,3 & 0,1 & 0,0 & 0,0 & 0,0 \\
\hline Fev_3 & 36,4 & 63,6 & 57,9 & 42,1 & 29,7 & 70,3 & 36,4 & 15,3 & 6,4 & 2,7 & 1,1 & 0,5 & 0,2 & 0,1 & 0,0 & 0,0 \\
\hline Mar_1 & 51,7 & 48,3 & 44,3 & 55,7 & 43,2 & 56,8 & 51,7 & 28,8 & 16,1 & 9,0 & 5,0 & 2,8 & 1,5 & 0,9 & 0,5 & 0,3 \\
\hline Mar_2 & 46,2 & 53,8 & 41,1 & 58,9 & 40,9 & 59,1 & 46,2 & 27,2 & 16,0 & 9,4 & 5,5 & 3,3 & 1,9 & 1,1 & 0,7 & 0,4 \\
\hline Mar_3 & 59,6 & 40,4 & 34,8 & 65,2 & 40,7 & 59,3 & 59,6 & 38,9 & 25,3 & 16,5 & 10,8 & 7,0 & 4,6 & 3,0 & 2,0 & 1,3 \\
\hline Abr_1 & 70,7 & 29,3 & 24,3 & 75,7 & 63,9 & 36,1 & 70,7 & 53,5 & 40,5 & 30,7 & 23,2 & 17,6 & 13,3 & 10,1 & 7,6 & 5,8 \\
\hline Abr_2 & 62,4 & 37,6 & 28,4 & 71,6 & 60,6 & 39,4 & 62,4 & 44,7 & 32,0 & 22,9 & 16,4 & 11,7 & 8,4 & 6,0 & 4,3 & 3,1 \\
\hline Abr_3 & 50,3 & 49,7 & 59,9 & 40,1 & 47,0 & 53,0 & 50,3 & 20,2 & 8,1 & 3,3 & 1,3 & 0,5 & 0,2 & 0,1 & 0,0 & 0,0 \\
\hline Mai_1 & 53,8 & 46,2 & 60,3 & 39,7 & 51,5 & 48,5 & 53,8 & 21,3 & 8,5 & 3,4 & 1,3 & 0,5 & 0,2 & 0,1 & 0,0 & 0,0 \\
\hline Mai_2 & 46,9 & 53,1 & 63,3 & 36,7 & 52,7 & 47,3 & 46,9 & 17,2 & 6,3 & 2,3 & 0,8 & 0,3 & 0,1 & 0,0 & 0,0 & 0,0 \\
\hline Mai_3 & 37,0 & 63,0 & 58,4 & 41,6 & 28,3 & 71,7 & 37,0 & 15,4 & 6,4 & 2,7 & 1,1 & 0,5 & 0,2 & 0,1 & 0,0 & 0,0 \\
\hline Jun_1 & 35,9 & 64,1 & 72,0 & 28,0 & 45,6 & 54,4 & 35,9 & 10,0 & 2,8 & 0,8 & 0,2 & 0,1 & 0,0 & 0,0 & 0,0 & 0,0 \\
\hline Jun_2 & 49,3 & 50,7 & 67,8 & 32,2 & 46,7 & 53,3 & 49,3 & 15,9 & 5,1 & 1,6 & 0,5 & 0,2 & 0,1 & 0,0 & 0,0 & 0,0 \\
\hline Jun_3 & 39,0 & 61,0 & 82,0 & 18,0 & 48,9 & 51,1 & 39,0 & 7,0 & 1,3 & 0,2 & 0,0 & 0,0 & 0,0 & 0,0 & 0,0 & 0,0 \\
\hline Jul_1 & 39,0 & 61,0 & 75,7 & 24,3 & 46,8 & 53,2 & 39,0 & 9,5 & 2,3 & 0,6 & 0,1 & 0,0 & 0,0 & 0,0 & 0,0 & 0,0 \\
\hline Jul_2 & 43,1 & 56,9 & 78,3 & 21,7 & 38,2 & 61,8 & 43,1 & 9,4 & 2,0 & 0,4 & 0,1 & 0,0 & 0,0 & 0,0 & 0,0 & 0,0 \\
\hline Jul_3 & 52,7 & 47,3 & 82,9 & 17,1 & 39,1 & 60,9 & 52,7 & 9,0 & 1,5 & 0,3 & 0,0 & 0,0 & 0,0 & 0,0 & 0,0 & 0,0 \\
\hline Ago_1 & 59,7 & 40,3 & 88,4 & 11,6 & 54,0 & 46,0 & 59,7 & 6,9 & 0,8 & 0,1 & 0,0 & 0,0 & 0,0 & 0,0 & 0,0 & 0,0 \\
\hline Ago_2 & 64,8 & 35,2 & 84,9 & 15,1 & 59,6 & 40,4 & 64,8 & 9,8 & 1,5 & 0,2 & 0,0 & 0,0 & 0,0 & 0,0 & 0,0 & 0,0 \\
\hline Ago_3 & 65,2 & 34,8 & 84,9 & 15,1 & 58,1 & 41,9 & 65,2 & 9,8 & 1,5 & 0,2 & 0,0 & 0,0 & 0,0 & 0,0 & 0,0 & 0,0 \\
\hline Set_1 & 59,0 & 41,0 & 77,8 & 22,2 & 54,7 & 45,3 & 59,0 & 13,1 & 2,9 & 0,6 & 0,1 & 0,0 & 0,0 & 0,0 & 0,0 & 0,0 \\
\hline Set_2 & 44,8 & 55,2 & 76,7 & 23,3 & 37,2 & 62,8 & 44,8 & 10,4 & 2,4 & 0,6 & 0,1 & 0,0 & 0,0 & 0,0 & 0,0 & 0,0 \\
\hline Set_3 & 34,1 & 65,9 & 87,1 & 12,9 & 32,5 & 67,5 & 34,1 & 4,4 & 0,6 & 0,1 & 0,0 & 0,0 & 0,0 & 0,0 & 0,0 & 0,0 \\
\hline Out_1 & 39,0 & 61,0 & 74,6 & 25,4 & 33,3 & 66,7 & 39,0 & 9,9 & 2,5 & 0,6 & 0,2 & 0,0 & 0,0 & 0,0 & 0,0 & 0,0 \\
\hline Out_2 & 42,4 & 57,6 & 62,1 & 37,9 & 33,1 & 66,9 & 42,4 & 16,1 & 6,1 & 2,3 & 0,9 & 0,3 & 0,1 & 0,0 & 0,0 & 0,0 \\
\hline Out_3 & 46,1 & 53,9 & 56,4 & 43,6 & 37,1 & 62,9 & 46,1 & 20,1 & 8,8 & 3,8 & 1,7 & 0,7 & 0,3 & 0,1 & 0,1 & 0,0 \\
\hline Nov_1 & 45,2 & 54,8 & 53,5 & 46,5 & 36,4 & 63,6 & 45,2 & 21,0 & 9,8 & 4,5 & 2,1 & 1,0 & 0,5 & 0,2 & 0,1 & 0,0 \\
\hline Nov_2 & 43,1 & 56,9 & 47,4 & 52,6 & 33,4 & 66,6 & 43,1 & 22,7 & 11,9 & 6,3 & 3,3 & 1,7 & 0,9 & 0,5 & 0,3 & 0,1 \\
\hline Nov_3 & 54,1 & 45,9 & 44,7 & 55,3 & 44,7 & 55,3 & 54,1 & 29,9 & 16,5 & 9,1 & 5,0 & 2,8 & 1,5 & 0,9 & 0,5 & 0,3 \\
\hline Dez_1 & 45,5 & 54,5 & 41,7 & 58,3 & 39,6 & 60,4 & 45,5 & 26,5 & 15,5 & 9,0 & 5,3 & 3,1 & 1,8 & 1,0 & 0,6 & 0,4 \\
\hline Dez_2 & 37,6 & 62,4 & 53,4 & 46,6 & 29,5 & 70,5 & 37,6 & 17,5 & 8,2 & 3,8 & 1,8 & 0,8 & 0,4 & 0,2 & 0,1 & 0,0 \\
\hline Dez_3 & 48,6 & 51,4 & 38,9 & 61,1 & 37,7 & 62,3 & 48,6 & 29,7 & 18,1 & 11,1 & 6,8 & 4,1 & 2,5 & 1,5 & 0,9 & 0,6 \\
\hline Média & 47,4 & 52,6 & 59,5 & 40,5 & 41,6 & 58,4 & 47,4 & 19,5 & 9,7 & 5,4 & 3,2 & 2,0 & 1,3 & 0,9 & 0,6 & 0,4 \\
\hline DP & 9,9 & 9,9 & 18,1 & 18,1 & 10,4 & 10,4 & 9,9 & 11,2 & 9,2 & 6,9 & 5,0 & 3,6 & 2,7 & 2,0 & 1,5 & 1,1 \\
\hline
\end{tabular}


Tabela 5. Probabilidades simples, probabilidades condicionais e probabilidades de dias consecutivos favoráveis ao preparo mecanizado do solo e suas respectivas probabilidades média e desvio padrão (DP) em cada decêndio do ano em Dourados, MS.

\begin{tabular}{|c|c|c|c|c|c|c|c|c|c|c|c|c|c|c|c|c|}
\hline \multirow{2}{*}{ Decêndios } & \multicolumn{6}{|c|}{ Probabilidades simples e condicionais (\%) } & \multicolumn{10}{|c|}{ Probabilidades de dias consecutivos favoráveis (\%) } \\
\hline & $\mathrm{P}(\mathrm{F})$ & $\mathrm{P}(\mathrm{NF})$ & $\mathrm{P}(\mathrm{NF} / \mathrm{F})$ & $\mathrm{P}(\mathrm{F} / \mathrm{F})$ & $\mathrm{P}(\mathrm{F} / \mathrm{NF})$ & $\mathrm{P}(\mathrm{NF} / \mathrm{NF})$ & $\mathrm{P}(1)$ & $\mathrm{P}(2)$ & $\mathrm{P}(3)$ & $\mathrm{P}(4)$ & $\mathrm{P}(5)$ & $\mathrm{P}(6)$ & $\mathrm{P}(7)$ & $\mathrm{P}(8)$ & $\mathrm{P}(9)$ & $\mathrm{P}(10)$ \\
\hline Jan_1 & 54,5 & 45,5 & 40,3 & 59,7 & 46,3 & 53,7 & 54,5 & 32,5 & 19,4 & 11,6 & 6,9 & 4,1 & 2,5 & 1,5 & 0,9 & 0,5 \\
\hline Jan_2 & 41,7 & 58,3 & 48,3 & 51,7 & 33,7 & 66,3 & 41,7 & 21,6 & 11,1 & 5,8 & 3,0 & 1,5 & 0,8 & 0,4 & 0,2 & 0,1 \\
\hline Jan_3 & 45,1 & 54,9 & 53,1 & 46,9 & 39,9 & 60,1 & 45,1 & 21,2 & 9,9 & 4,7 & 2,2 & 1,0 & 0,5 & 0,2 & 0,1 & 0,0 \\
\hline Fev_1 & 57,6 & 42,4 & 41,0 & 59,0 & 42,5 & 57,5 & 57,6 & 34,0 & 20,0 & 11,8 & 7,0 & 4,1 & 2,4 & 1,4 & 0,8 & 0,5 \\
\hline Fev_2 & 61,0 & 39,0 & 41,6 & 58,4 & 58,0 & 42,0 & 61,0 & 35,6 & 20,8 & 12,2 & 7,1 & 4,1 & 2,4 & 1,4 & 0,8 & 0,5 \\
\hline Fev_3 & 50,3 & 49,7 & 45,4 & 54,6 & 45,9 & 54,1 & 50,3 & 27,5 & 15,0 & 8,2 & 4,5 & 2,4 & 1,3 & 0,7 & 0,4 & 0,2 \\
\hline Mar_1 & 54,8 & 45,2 & 42,0 & 58,0 & 52,7 & 47,3 & 54,8 & 31,8 & 18,4 & 10,7 & 6,2 & 3,6 & 2,1 & 1,2 & 0,7 & 0,4 \\
\hline Mar_2 & 53,1 & 46,9 & 37,4 & 62,6 & 46,0 & 54,0 & 53,1 & 33,2 & 20,8 & 13,0 & 8,1 & 5,1 & 3,2 & 2,0 & 1,3 & 0,8 \\
\hline Mar_3 & 54,9 & 45,1 & 35,7 & 64,3 & 49,1 & 50,9 & 54,9 & 35,3 & 22,7 & 14,6 & 9,4 & 6,0 & 3,9 & 2,5 & 1,6 & 1,0 \\
\hline Abr_1 & 59,7 & 40,3 & 33,9 & 66,1 & 56,4 & 43,6 & 59,7 & 39,4 & 26,1 & 17,2 & 11,4 & 7,5 & 5,0 & 3,3 & 2,2 & 1,4 \\
\hline Abr_2 & 53,8 & 46,2 & 36,6 & 63,4 & 49,2 & 50,8 & 53,8 & 34,1 & 21,6 & 13,7 & 8,7 & 5,5 & 3,5 & 2,2 & 1,4 & 0,9 \\
\hline Abr_3 & 62,4 & 37,6 & 45,5 & 54,5 & 57,8 & 42,2 & 62,4 & 34,0 & 18,5 & 10,1 & 5,5 & 3,0 & 1,6 & 0,9 & 0,5 & 0,3 \\
\hline Mai_1 & 57,6 & 42,4 & 56,9 & 43,1 & 56,2 & 43,8 & 57,6 & 24,8 & 10,7 & 4,6 & 2,0 & 0,9 & 0,4 & 0,2 & 0,1 & 0,0 \\
\hline Mai_2 & 56,9 & 43,1 & 56,5 & 43,5 & 60,4 & 39,6 & 56,9 & 24,8 & 10,8 & 4,7 & 2,0 & 0,9 & 0,4 & 0,2 & 0,1 & 0,0 \\
\hline Mai_3 & 48,0 & 52,0 & 55,5 & 44,5 & 37,0 & 63,0 & 48,0 & 21,3 & 9,5 & 4,2 & 1,9 & 0,8 & 0,4 & 0,2 & 0,1 & 0,0 \\
\hline Jun_1 & 54,1 & 45,9 & 48,7 & 51,3 & 57,8 & 42,2 & 54,1 & 27,8 & 14,2 & 7,3 & 3,7 & 1,9 & 1,0 & 0,5 & 0,3 & 0,1 \\
\hline Jun_2 & 63,8 & 36,2 & 49,5 & 50,5 & 55,5 & 44,5 & 63,8 & 32,2 & 16,3 & 8,2 & 4,2 & 2,1 & 1,1 & 0,5 & 0,3 & 0,1 \\
\hline Jun_3 & 59,7 & 40,3 & 57,0 & 43,0 & 62,2 & 37,8 & 59,7 & 25,6 & 11,0 & 4,7 & 2,0 & 0,9 & 0,4 & 0,2 & 0,1 & 0,0 \\
\hline Jul_1 & 63,4 & 36,6 & 52,9 & 47,1 & 68,4 & 31,6 & 63,4 & 29,9 & 14,1 & 6,6 & 3,1 & 1,5 & 0,7 & 0,3 & 0,2 & 0,1 \\
\hline Jul_2 & 53,4 & 46,6 & 66,7 & 33,3 & 53,1 & 46,9 & 53,4 & 17,8 & 5,9 & 2,0 & 0,7 & 0,2 & 0,1 & 0,0 & 0,0 & 0,0 \\
\hline Jul_3 & 43,9 & 56,1 & 67,4 & 32,6 & 31,6 & 68,4 & 43,9 & 14,3 & 4,7 & 1,5 & 0,5 & 0,2 & 0,1 & 0,0 & 0,0 & 0,0 \\
\hline Ago_1 & 42,1 & 57,9 & 84,6 & 15,4 & 38,2 & 61,8 & 42,1 & 6,5 & 1,0 & 0,2 & 0,0 & 0,0 & 0,0 & 0,0 & 0,0 & 0,0 \\
\hline Ago_2 & 38,3 & 61,7 & 81,3 & 18,7 & 37,4 & 62,6 & 38,3 & 7,1 & 1,3 & 0,2 & 0,0 & 0,0 & 0,0 & 0,0 & 0,0 & 0,0 \\
\hline Ago_3 & 25,4 & 74,6 & 80,7 & 19,3 & 20,6 & 79,4 & 25,4 & 4,9 & 0,9 & 0,2 & 0,0 & 0,0 & 0,0 & 0,0 & 0,0 & 0,0 \\
\hline Set_1 & 16,9 & 83,1 & 88,4 & 11,6 & 12,5 & 87,5 & 16,9 & 2,0 & 0,2 & 0,0 & 0,0 & 0,0 & 0,0 & 0,0 & 0,0 & 0,0 \\
\hline Set_2 & 29,3 & 70,7 & 75,9 & 24,1 & 26,5 & 73,5 & 29,3 & 7,1 & 1,7 & 0,4 & 0,1 & 0,0 & 0,0 & 0,0 & 0,0 & 0,0 \\
\hline Set_3 & 37,9 & 62,1 & 70,7 & 29,3 & 32,9 & 67,1 & 37,9 & 11,1 & 3,3 & 1,0 & 0,3 & 0,1 & 0,0 & 0,0 & 0,0 & 0,0 \\
\hline Out_1 & 47,6 & 52,4 & 57,9 & 42,1 & 46,2 & 53,8 & 47,6 & 20,0 & 8,4 & 3,5 & 1,5 & 0,6 & 0,3 & 0,1 & 0,0 & 0,0 \\
\hline Out_2 & 52,8 & 47,2 & 53,5 & 46,5 & 37,9 & 62,1 & 52,8 & 24,5 & 11,4 & 5,3 & 2,5 & 1,1 & 0,5 & 0,2 & 0,1 & 0,1 \\
\hline Out_3 & 50,2 & 49,8 & 43,8 & 56,2 & 40,7 & 59,3 & 50,2 & 28,2 & 15,9 & 8,9 & 5,0 & 2,8 & 1,6 & 0,9 & 0,5 & 0,3 \\
\hline Nov_1 & 57,2 & 42,8 & 55,1 & 44,9 & 53,3 & 46,7 & 57,2 & 25,7 & 11,5 & 5,2 & 2,3 & 1,0 & 0,5 & 0,2 & 0,1 & 0,0 \\
\hline Nov_2 & 62,4 & 37,6 & 31,5 & 68,5 & 48,4 & 51,6 & 62,4 & 42,7 & 29,3 & 20,1 & 13,7 & 9,4 & 6,4 & 4,4 & 3,0 & 2,1 \\
\hline Nov_3 & 61,4 & 38,6 & 37,4 & 62,6 & 48,0 & 52,0 & 61,4 & 38,4 & 24,1 & 15,1 & 9,4 & 5,9 & 3,7 & 2,3 & 1,5 & 0,9 \\
\hline Dez_1 & 53,4 & 46,6 & 45,9 & 54,1 & 52,4 & 47,6 & 53,4 & 28,9 & 15,6 & 8,4 & 4,6 & 2,5 & 1,3 & 0,7 & 0,4 & 0,2 \\
\hline Dez_2 & 52,8 & 47,2 & 33,4 & 66,6 & 44,5 & 55,5 & 52,8 & 35,1 & 23,4 & 15,6 & 10,4 & 6,9 & 4,6 & 3,1 & 2,0 & 1,4 \\
\hline Dez_3 & 56,1 & 43,9 & 39,7 & 60,3 & 44,8 & 55,2 & 56,1 & 33,8 & 20,4 & 12,3 & 7,4 & 4,5 & 2,7 & 1,6 & 1,0 & 0,6 \\
\hline Média & 50,9 & 49,1 & 52,6 & 47,4 & 45,7 & 54,3 & 50,9 & 25,4 & 13,6 & 7,6 & 4,4 & 2,6 & 1,5 & 0,9 & 0,6 & 0,4 \\
\hline DP & 10,8 & 10,8 & 15,5 & 15,5 & 11,9 & 11,9 & 10,8 & 10,7 & 7,9 & 5,5 & 3,7 & 2,5 & 1,7 & 1,1 & 0,7 & 0,5 \\
\hline
\end{tabular}


Os resultados apresentados neste estudo indicam o imenso potencial das ferramentas agrometeorológicas para o planejamento das atividades agrícolas de campo, neste caso, mais especificamente para operações que exigem o revolvimento do solo, como o preparo (aração, gradagem e plantio) e o manejo (construção de terraços e subsolagem) (Wadt et al., 2003).

\section{CONCLUSÕES}

De acordo com os resultados obtidos, pode-se concluir que:

a) a variabilidade anual das condições de chuva e armazenamento de água no solo permitiu identificar os períodos do ano com favorabilidades baixa, média e alta às operações com máquinas para o preparo e o manejo do solo;

b) a aplicação da técnica da cadeia de Markov mostrou-se como uma ferramenta eficiente para a determinação da sequencia de dias favoráveis ao preparo e o manejo do solo, auxiliando no planejamento das atividades de campo;

c) dentre as localidades analisadas houve predomínio de um número médio de dias trabalháveis, entre 11 e 20 dias, na grande maioria dos meses, exceto para Londrina onde houve uma maior predominância de um baixo número de dias trabalháveis por mês ao longo do ano, ou seja, com até 10 dias.

\section{AGRADECIMENTOS}

Os autores agradecem à EMBRAPA-Trigo, em Passo Fundo, RS, à EMBRAPAAgropecuária Oeste, em Dourados, MS, ao IAPAR, em Londrina, PR, e à ESALQ/USP, em Piracicaba, SP, pelo fornecimento dos dados meteorológicos empregados no presente estudo. $\mathrm{O}$ segundo autor agradece ao $\mathrm{CNPq}$ pela bolsa de produtividade em pesquisa.

\section{REFERÊNCIAS}

ARAUjO, M. A.; TORMENA, C. A.; SILVA, A. P. Propriedades físicas de um latossolo vermelho distrófico cultivado e sob mata nativa. Revista Brasileira de Ciência do Solo, v. 28, n. 2, p. 337-345, 2004. http://dx.doi.org/10.1590/S010006832004000200012

ASSIS, F. N.; VILLA NOVA, N. A. Modelagem da ocorrência e da quantidade da chuva em Piracicaba. Scientia Agricola, v. 51, n. 3, p. 172-182, 1995.

ATAÍDE, L. T.; CARAMORI, P. H.; RICCE, W. S.; SILVA, D. A. B.; SOUZA, J. R. P. The probability of potentially useful work days during the year in Londrina. Semina, v. 33, n. 6, p. 2215-2226, 2012. http://dx.doi.org/10.5433/1679-0359.2012v33n6p2215

AVIAD, Y.; KUTIEL, H.; LAVEE, H. Variation of Dry Days Since Last Rain (DDSLR) as a measure of dryness along a Mediterranean - Arid transect. Journal of Arid Environments, v. 73, n. 6/7, p. 658-665, 2009.

http://dx.doi.org/10.1016/j.jaridenv.2009.01.012

BLAIN, G. C.; PIEDADE, S. M. S.; CAMARGO, M. B. P.; GIAROLLA, A. Distribuição temporal da precipitação pluvial mensal observada no posto meteorológico do Instituto Agronômico, em Campinas, SP. Bragantia, v. 66, n. 2, p. 347-355, 2007. http://dx.doi.org/10.1590/S0006-87052007000200019 
CAMARGO, A. P.; MARIN, F. R.; SENTELHAS, P. C.; PICINI, A. G. Ajuste da equação de Thornthwaite para estimar a evapotranspiração potencial em climas áridos $\mathrm{e}$ superúmidos, com base na amplitude térmica diária. Revista Brasileira de Agrometeorologia, v. 7, n. 2, p. 251-257, 1999.

CAMILOTTI, F.; ANDRIOLI, I.; DIAS, F. L. F.; CASAGRANDE, A. A.; SILVA, A. R.; MUTTON, M. A. et al. Efeito prolongado de sistemas de preparo do solo com e sem cultivo de soqueira de cana crua em algumas propriedades físicas do solo. Engenharia Agrícola, v. 25, n. 1, p. 189-198, 2005. http://dx.doi.org/10.1590/S010069162005000100021

CHEN, G.; WEIL, R. R. Root growth and yield of maize as affected by soil compaction and cover crops. Soil and Tillage Research, v. 117, p. 17-27, 2011. http://dx.doi.org/10.1016/j.still.2011.08.001

COSTA, F. S.; ALBUQUERQUE, J. A.; BAYER, C.; FONTOURA, S. M. V.; WOBETO, C. Propriedades físicas de um Latossolo Bruno afetadas pelos sistemas plantio direto e preparo convencional. Revista Brasileira de Ciência do Solo, v. 27, n. 3, p. 527-535, 2003. http://dx.doi.org/10.1590/S0100-06832003000300014

ERTHAL, L. C.; SENTELHAS, P. C. Probabilidade da sequência de dias secos em Campinas (SP) como subsídio ao planejamento do uso de máquinas agrícolas. In: CONGRESSO BRASILEIRO DE AGROMETEOROLOGIA, 9., 1995, Campinas Grande, PB. Anais... Campina Grande: CCT/UFPb; Sociedade Brasileira de Agrometeorologia, 1995. p. 409411.

FIETZ, C. R.; URCHEI, M. A.; FRIZZONE, J. A. Probabilidade de ocorrência de déficit hídrico na região de Dourados, MS. Revista Brasileira de Engenharia Agrícola e Ambiental, v. 5, n. 3, p. 558-562, 2001. http://dx.doi.org/10.1590/S141543662001000300031

GABRIEL, K. R.; NEUMANN, J. A. Markov chain model for daily rainfall occurrences at Tel Aviv. Quarterly journal of the Royal Meteorological Society, n. 88, p. 90-95, 1962. http://dx.doi.org/10.1002/qj.49708837511

GOMES, A. A.; MUSSURY, R. M.; SCALON, S. P. Q.; WATTHIER, F.; CUNHA, K. A. A.; SCALON FILHO, H. Avaliação do impacto da fragmentação de florestas nativas sobre a mesofauna edáfica na região de Dourados-MS. Ciência e Agrotecnologia, v. 31, n. 3, p. 612-618, 2007. http://dx.doi.org/10.1590/S1413-70542007000300003

HEMMAT, A.; TAHMASEBI, M.; VAFAEIAN, M.; MOSADDEGHI, M. R. Relationship between pre-compaction stress and shear strength under confined and semi-confined loadings for a sandy loam soil. Biosystems Engineering, v. 102, p. 219-226, 2009. http://dx.doi.org/10.1016/j.biosystemseng.2008.11.001

MARCUZZO, F. F. N.; MELO, D. C. R.; COSTA, H. C. Sazonalidade e distribuição espaçotemporal das chuvas no bioma do Cerrado do Estado do Mato Grosso do Sul. Revista Brasileira de Recursos Hídricos, v. 17, p. 77-86, 2012.

MARTIN-VERTEDOR, A. I.; DODD, I. C. Root-to-shoot signalling when soil moisture is heterogeneous: increasing the proportion of root biomass in drying soil inhibits leaf growth and increases leaf abscisic acid concentration. Plant, Cell and Environment, v. 34, p. 1164-1175, 2011. http://dx.doi.org/10.1111/j.1365-3040.2011.02315.x 
OLIVEIRA, G. C.; DIAS JÚNIOR, M. S.; RESCK, D. V. S.; CURI, N. Alterações estruturais e comportamento compressivo de um Latossolo Vermelho distrófico argiloso sob diferentes sistemas de uso e manejo. Pesquisa Agropecuária Brasileira, v. 38, n. 2, p. 291-299, 2003. http://dx.doi.org/10.1590/S0100-204X2003000200017

ROBERTSON, G. W. Dry and wet spells. Malaysia: Project Field Report, 1976. 28p.

ROWHANI, P.; LOBELL, D. B.; LINDERMAN, M.; RAMANKUTTY, N. Climate variability and crop production in Tanzania. Agricultural and Forest Meteorology, v. 151, p.449-460, 2011. http://dx.doi.org/10.1016/j.agrformet.2010.12.002

RÜCKNAGEL, J.; CHRISTEN, O.; HOFMANN, B.; ULRICH, S. A simple model to estimate change in precompression stress as a function of water content on the basis of precompression stress at field capacity. Geoderma, v. 177, p. 1-7, 2012. http://dx.doi.org/10.1016/j.geoderma.2012.01.035

SAMPAIO, S. C.; LONGO, A. J.; QUEIROZ, M. M. F.; GOMES, B. M.; VILAS BOAS, M. A.; SUSZEK, M. Estimativa e distribuição da precipitação mensal provável no Estado do Paraná. Acta Scientiarum, v. 28, n. 2, p.267-272, 2007.

SEVERIANO, E. C.; OLIVEIRA, G. C.; DIAS JUNIOR, M. S.; OLIVEIRA, L. F. C.; CASTRO, M. B. Pressão de preconsolidação e intervalo hídrico ótimo como indicadores de alterações estruturais de um latossolo e de um cambissolo sob cana-deaçúcar. Revista Brasileira de Ciência do Solo, v. 32, n. 4, p. 1419-1427, 2008. http://dx.doi.org/10.1590/S0100-06832008000400006

SILVA, R. V.; REINERT, D. J.; REICHERT, J. M.; SOARES, J. M. Fatores controladores da compressibilidade de um Argissolo Vermelho-Amarelo distrófico arênico e de um Latossolo Vermelho distrófico típico. I - Estado inicial de compactação. Revista Brasileira de Ciência do Solo, v. 26, p. 1-8, 2002.

SOUZA, Z.M.; PRADO, R.M.; PAIXÃO, A.C.S.; CESARIN, L.G. Sistemas de colheita e manejo da palhada de cana-de-açúcar. Pesquisa Agropecuária Brasileira, v. 40, n. 3, p. 271-278, 2005. http://dx.doi.org/10.1590/S0100-204X2005000300011

SPERA, S. T.; DENARDIN, J. E.; ESCOSTEGUY, P. A. V.; SANTOS, H. P.; FIGUEROA, E. A. Dispersão de argila em microagregados de solo incubado com calcário. Revista Brasileira de Ciência do Solo, v. 32, n. especial, p. 2613-2620, 2008. http://dx.doi.org/10.1590/S0100-06832008000700002

STRECK, N. A.; BURIOL, G. A.; HELDWEIN, A. B.; GABRIEL, L. F.; PAULA, G. M. Associação da variabilidade da precipitação pluvial em Santa Maria com a Oscilação Decadal do Pacífico. Pesquisa Agropecuária Brasileira, v. 44, n. 12, p. 1553-1561, 2009. http://dx.doi.org/10.1590/S0100-204X2009001200001

TERAMOTO, E. R.; LEPSCH, I. F.; VIDAL-TORRADO, P. V. Relações solo, superfície geomorfológica e substrato geológico na microbacia do Ribeirão Martins (Piracicaba SP). Scientia Agricola, v. 58, n. 2, p. 361-371, 2001. http://dx.doi.org/10.1590/S010390162001000200021

THORNTHWAITE, C. W.; MATHER, J.R. The water balance. Centerton: Drexel Institute of Tecnology, 1955. 104p. (Publications in climatology, 8, n .1). 
WADT, P. G. S.; PEREIRA, J. E. S.; GONÇALVES, R. C.; SOUZA, C. B. C.; ALVES, L. S. Práticas de conservação de solo e recuperação de áreas degradadas. Rio Branco: EMBRAPA Acre, 2003. 29p. (Documentos EMBRAPA Acre 90).

ZANETTI, S. V.; SAMPAIO, S. C.; SILVESTRE, M. G.; BOAS, M. A.V.; URIBE-OPAZO, M. A.; QUEIROZ, M. M. F. Análise espacial da umidade do solo cultivado com soja sob dois sistemas de manejo. Revista Brasileira de Engenharia Agrícola e Ambiental, v. 11, n. 3, p. 239-247, 2007. http://dx.doi.org/10.1590/S141543662007000300001 